\title{
Noise exposure and hypertension: investigation of a silent relationship
}

\author{
Tatiana Cristina Fernandes de Souza ${ }^{1}$, André Reynaldo Santos Périssé ${ }^{2 *}$ and Marisa Moura ${ }^{1}$
}

\begin{abstract}
Background: Noise is an important occupational hazard worldwide and hypertension a well-known risk factor for cardiovascular disease, which is currently the greatest cause of disability retirement worldwide. The association between noise exposure and auditory effects is well documented in the biomedical literature, but the same is not true about exposure to different levels of noise and extra-auditory effects. It has been shown that noise exposure levels to be considered for non-auditory effects may not be the same as in the case of auditory effects. The frequent presence of noise in workplace environments, the high prevalence of hypertension worldwide, the biological plausibility of the association between noise exposure and high blood pressure and the need for more studies investigating the non-auditory effects of exposures to less than $85 \mathrm{~dB}(\mathrm{~A})$, were the reasons that led us to develop this study. We aimed at investigating the hypothesis that exposure to different levels of noise is associated with hypertension.
\end{abstract}

Methods: We used a cross-sectional design to study the association between occupational noise exposure $(\leq 75,75-85$, and $\geq 85 \mathrm{~dB}(\mathrm{~A})$ ) and hypertension (use of anti-hypertensive medication and/or blood pressure of $\geq 140 / 90 \mathrm{mmHg}$ ) in 1,729 petrochemical workers at Rio de Janeiro, Brazil. Data were collected from obligatory annual health evaluation records and from environmental measurements of noise and heat levels. We used logistical regression analysis to study the association while controlling for key confounding variables, such as smoking and body mass index.

Results: Using the $\leq 75 \mathrm{~dB}(\mathrm{~A})$ as reference category, noise exposure was independently associated to hypertension both at the 75-85 dB(A) (OR 1.56; 95\% Cl 1.13-2.17) and the $\geq 85 \mathrm{~dB}(\mathrm{~A})$ levels (OR 1.58; 95\% Cl 1.10-2.26). Age, gender and body mass index were also independently associated to high blood pressure.

Conclusion: Herein, we were able to demonstrate that noise exposure is independently associated to hypertension. Our results are consistent with other studies that used similar methodology and enabled us to verify the occurrence of non-auditory effects in workers exposed to noise levels considered safe for auditory effects.

Keywords: Occupational Noise, Hypertension, High Blood Pressure, Occupational Exposure, Occupational Health

\section{Background}

Hearing loss is the most investigated and accepted health effect related to noise exposure [1-4]. However, other health effects such as digestive and behavioral disorders [5], sleep disturbances [6], changes in the serum cortisol levels [7], cardiovascular diseases [8] and a higher incidence of occupational accidents $[9,10]$ may also be associated to noise exposure.

Studies of the association between noise and outcomes not related to hearing disease are usually based on

\footnotetext{
* Correspondence: aperisse@ensp.fiocruz.br

${ }^{2}$ Departamento de Ciências Biológicas, Escola Nacional de Saúde Pública Sergio Arouca, Fundação Oswaldo Cruz (DCB/ENSP/Fiocruz), Rua Leopoldo Bulhões 1480, Manguinhos, Rio de Janeiro/RJ, Brazil

Full list of author information is available at the end of the article
}

analogies to the hearing effects of noise, and the maximum exposure limits for hearing effects $(85 \mathrm{~dB}(\mathrm{~A}))$ is usually also considered for non-hearing outcomes [11]. However, there are evidences that lower level exposure to noise is associated to other health effects. Berglung et al. [12] reviewed the biomedical evidence of the association between noise exposure and non-hearing effect and were able to show a higher level of stress among individuals exposed to $55 \mathrm{~dB}(\mathrm{~A})$ and cardiovascular disturbances in individuals exposed to more than $65 \mathrm{dBA}$.

Cardiovascular diseases was one of the leading causes of death and years of life lost due to premature mortality (YLLs) in the 2010 report of global burden of disease [13]. High blood pressure is highly associated to cardiovascular 
disease and its high prevalence worldwide makes it one of the three leading risk factor for global disease burden [14]. The World Health Organization (WHO) estimated that, in 2008, 30\% of the adults in the WHO European Region and $23 \%$ in the WHO Region of the Americas had high blood pressure [15]. Almost 9.5 million deaths each year, or $16.5 \%$ of all deaths worldwide can be attributed to high blood pressure [14]. According to the Brazilian Hypertension Society, high blood pressure affects, on average, $25 \%$ of the Brazilian population [16].

The hypothesis that exposure to excessive noise could be associated to high blood pressure was described by Babisch [8] who showed that the association could be explained by the biochemical changes related to the mechanisms of stress. Briefly, an increase in the level of chemical substances like cortisol, adrenaline and noradrenaline in response to the stress caused by noise could result in peripheral vasoconstriction, increased heart rate, and increased arterial blood pressure [11,17-19]. In workplace environments, other stress-generated situations sharing with noise the same physiopathological mechanism may exist, which may contribute to the high prevalence and incidence of hypertension in these locations [20-23].

The frequent presence of noise in workplace environments, the high prevalence of hypertension worldwide, the biological plausibility of the association between noise exposure and high blood pressure and the need for more studies investigating the non-auditory effects of exposures to less than $85 \mathrm{~dB}(\mathrm{~A})$, were the reasons that led us to develop this study.

\section{Methods}

\section{Study design and population}

To address the main question of the association between noise exposure and high blood pressure, we performed a cross-sectional study design of existent secondary health and noise exposure data from 2007 related to workers of a petrochemical and gas refinery in Rio de Janeiro, Brazil.

The studied unit has two types of work force: contractors (workers paid by the government) and sub-contractors (workers paid by outsourced corporations). The two workforces are subject to different labor legislations and all outsourced corporations are required to perform preadmission and annual health examination in every worker. Subcontracted labor force was working on the plant maintenance and expansion, while government workers were more involved in administrative tasks in the plant. Our sample framework was based only on workers from outsourced corporations (sub-contractor workers) since data was available only to them. We used the 6-month timeframe in order to guarantee a minimum period of noise exposure before the diagnosis of hypertension. The total number of subcontractor workers was 3,023 individuals, but our study was restricted to the 1,729 individuals working at the petrochemical industry for at least 6 months and submitted to annual physical exam in 2007.

\section{Health, socioeconomic and environmental data}

To elaborate our dataset we collected information from the electronic clinical forms of workers submitted to the annual mandatory health evaluation.

The variable age was stratified in five-year intervals. Civil status was dichotomized in married and single/divorced individuals, the only available categories. Formal education was reclassified in completed or incomplete elementary school, middle school, high school and college. Physical activity, tobacco use and alcohol consumption were defined according to the clinical form. Thus, regular physical activity included any activity for at least three times a week and a minimum duration of 20 minutes. Regular alcohol consumption was attributed to individuals informing daily alcohol ingestion, occasional consumption to individuals informing alcohol use only on weekends, and individuals informing no alcohol consumption were classified as no consumption. No data were available about the amount, type of alcoholic beverage and history of alcohol consumption. Alcohol consumption data was further categorized in consumption and no consumption, which encompassed those that consumed alcoholic beverages both occasionally and regularly. Body Mass Index (BMI) was calculated from the values of weight and height and categorized as normal (underweight $-<18.50 \mathrm{Kg} / \mathrm{m}^{2}$ and normal - 18.50-24.99 Kg/m²), overweight (25.00-29.99 $\left.\mathrm{Kg} / \mathrm{m}^{2}\right)$ and obese $\left(\geq 30.00 \mathrm{Kg} / \mathrm{m}^{2}\right)$ according to the WHO criteria [24]. Heating exposure was classified as exposed, when an individual was found to be exposed to values equal to or higher than 30 WBGTI (Wet Bulb Globe Thermometer Index) by the time of the measurement, according to a methodology recommended by the Fundacentro [25].

Traditional socioeconomic variables were not available in the forms from the annual mandatory health evaluation. Therefore, we used all available information that could be linked to the social condition of the workers. Hence, presence of running water, regular trash collection, sewage network and electrical power were used to create a composite indicator in which each of the four variables was classified as absent (0) or present (1), assuming equal importance to all variables. The socioeconomic indicator was classified as higher if all four variables were present and lower if at least one variable was absent.

There were several sectors distributed along the different subcontracted firms and with different levels of exposure to noise, and we were unable to obtain a correct estimate of the location of the workers per sector. Therefore, we opted for grouping the workers by the type of work in the industry as in "industrial maintenance", 
"cleaning and building maintenance", "civil works" and "others" (meals, transportation and security).

\section{Definition of exposure and outcome}

The outcome (high blood pressure) was defined as systolic pressure equal to or higher than $140 \mathrm{mmHg}$ and/or a diastolic pressure equal to or higher than $90 \mathrm{mmHg}$ [26]. Any worker reporting the use of anti-hypertensive medication was also classified as hypertensive, regardless of the measured pressure level. Blood pressure was measured by the attendant physician once at the beginning of the medical consultation, always on the left arm of a patient seated. In cases in which the blood pressure measurement was above the cut-off limits, a second measurement was performed at the end of the consultation. In these situations, only the second measurement was reported in the medical records.

Exposure to noise was measured at Homogeneous Exposure Groups (HEG) by using a digital audio dosimeter affixed next to their aural point to a randomly selected worker within the HEG. The measurement was done at a single moment in cases of continuous exposure to noise and during at least $75 \%$ of a workday of 8 hours in cases of intermittent exposure to noise, according to the Fundacentro methodology [27]. We categorized noise exposure in three levels: $\leq 75 \mathrm{~dB}(\mathrm{~A})$, from 75 to $85 \mathrm{~dB}$ (A), and $\geq 85 \mathrm{~dB}(\mathrm{~A})$. We based our decision to use the three level categorization on some studies that also considered lower levels for noise exposure [12,22,28].

\section{Statistical analysis}

Since the available dataset was not created to be used in a research project, not all-important variables were readily available to be used in the statistical analyzes. We decided to analyze confounding and interaction terms on any available variable with some indication in the biomedical literature of association to either noise exposure or high blood pressure. Therefore, age, gender, marital status, education, socioeconomic condition, physical activity, tobacco use, alcohol consumption, body mass index (BMI), type of service and heat exposure were the co-variables used in our analysis.

We began our data analysis by describing the frequency distribution of all variables according to the level of noise exposure. Thereafter, we performed a bivariate analysis for the association between all co-variables and both the exposure and the outcome variables in order to identify possible confounding variables for the studied association. All variables were categorized and a Chi-squared test used to test the associations. Any variable associated to the outcome with a p-value of at least $<0.15$ was considered to be included in the final multivariate model.

First order interactions terms between noise and age, gender, socioeconomic condition, physical activity, tobacco use, consumption of alcohol, body mass index and exposure to heat were individually tested and considered for the inclusion in the final multivariate model. Therefore, the baseline multivariate model was composed by all variables with a p-value of less than 0.15 in the exploratory analysis and statistically significant interaction terms. A logistic regression model with backward Wald elimination was used to model the independent association between noise exposure and high blood pressure, while considering other possible confounding variables. We present the final multivariate model only with variables statistically associated with high blood pressure since addition of non-significant variables did not add to the fitness of the final logistic model. The final odds ratio represents the relative odds of presence of high blood pressure. Statistical analysis was performed with the statistical package SPSS (version 17; SPSS Inc. software products).

The study was approved by the Ethics Committee at the National School of Public Health (CEP/ENSP). We analyzed a secondary dataset with no identifiers and the study was granted with a consent form waiver by the CEP/ENSP.

\section{Results}

Data from 1,729 workers were included in our analysis. The prevalence of high blood pressure among sampled workers was approximately 25\% (430/1729) (Table 1). Fifty-five out of the 430 (12.7\%) individuals classified as hypertensive were already under medication. Twentytwo percent of the individuals were exposed to levels $\leq$ $75 \mathrm{~dB}(\mathrm{~A})(388 / 1,729), 50 \%$ to levels between 75 and $85 \mathrm{~dB}(\mathrm{~A})(871 / 1,729)$, and $27 \%$ were exposed to levels $\geq$ $85 \mathrm{~dB}(\mathrm{~A})(470 / 1,729)$. Most of the workers were male $(1,585 / 92 \%)$, younger than 40 years-old $(956 / 55 \%)$ and single (919/53\%). Men and married workers had a higher probability to be exposed to the highest level of noise ( $\mathrm{p}=0.00$ and $\mathrm{p}-0.01$, respectively). Fewer workers had college-level education (124/7\%) and workers with higher formal education were more likely to be exposed to lower levels of noise $(p=0.00)$. Regular physical activity was reported by $21 \%(\mathrm{n}=367)$ of the individuals and $58 \%(\mathrm{n}=1,011)$ of the workers were overweight or obese. Workers were mostly non-smoker $(1,346 / 78 \%)$ and not a regular consumer of alcohol $(n=1,078 / 62 \%)$. Most of the sampled population was involved in industrial maintenance (610/35\%) and civil construction services (615/ $35.6 \%)$. Approximately $90 \%$ of them $(n=1,526)$ of them were not exposed to heat, according to the used exposure criteria. Workers in industrial maintenance were more likely to be in the higher level of noise exposure group $(\mathrm{p}=0.00)$ as well as workers exposed to heat $(\mathrm{p}=0.00)$.

Prevalence of hypertension was higher among older workers, especially after age $50(n=134 / 47.2 \%)$ (Table 2). Prevalence of high blood pressure was also higher among 
Table 1 General characteristic of the sample by levels of noise exposure

\begin{tabular}{|c|c|c|c|c|}
\hline Variable & $\begin{array}{l}\leq 75 \mathrm{~dB}(\mathrm{~A}) \\
\mathrm{n}(\%) \\
\mathrm{n}=388\end{array}$ & $\begin{array}{l}75-85 \mathrm{~dB}(\mathrm{~A}) \\
n(\%) \\
n=871\end{array}$ & $\begin{array}{l}\geq 85 \mathrm{~dB}(\mathrm{~A}) \\
\mathrm{n}(\%) \\
n=470\end{array}$ & p-value \\
\hline \multicolumn{5}{|l|}{ Age (years) } \\
\hline$<30$ & $83(23,2)$ & $186(52,0)$ & $89(24,9)$ & 0.03 \\
\hline $30-34$ & $80(26,1)$ & $145(47,4)$ & $81(26,5)$ & \\
\hline $35-39$ & $56(19,2)$ & $158(54,1)$ & $78(26,7)$ & \\
\hline $40-44$ & $42(15,4)$ & $147(53,8)$ & $84(30,8)$ & \\
\hline $45-49$ & $47(21,8)$ & $107(49,5)$ & $62(28,7)$ & \\
\hline$\geq 50$ & $80(28,2)$ & $128(45,1)$ & $76(26,8)$ & \\
\hline \multicolumn{5}{|l|}{ Gender } \\
\hline Female & $82(56,9)$ & $60(41,7)$ & $2(1,4)$ & 0.00 \\
\hline Male & $306(19,3)$ & $811(51,2)$ & $468(29,5)$ & \\
\hline \multicolumn{5}{|l|}{ Marital status } \\
\hline Single & $212(23,1)$ & $485(52,8)$ & $222(24,2)$ & 0.01 \\
\hline Married & $176(21,7)$ & $386(47,7)$ & $248(30,6)$ & \\
\hline \multicolumn{5}{|l|}{ Education } \\
\hline Up to incomplete elementary school & $11(13,6)$ & $45(55,6)$ & $25(30,9)$ & 0.00 \\
\hline Complete elementary school & $24(18,0)$ & $62(46,6)$ & $47(35,3)$ & \\
\hline Incomplete middle school & $40(11,4)$ & $202(57,7)$ & $108(30,9)$ & \\
\hline Complete middle school & $45(14,9)$ & $173(57,3)$ & $84(27,8)$ & \\
\hline Incomplete high school & $39(19,3)$ & $96(47,5)$ & $67(33,2)$ & \\
\hline Complete high school & $157(29,2)$ & $252(46,9)$ & $128(23,8)$ & \\
\hline College/university (complete or not) & $72(58,1)$ & $41(33,1)$ & $11(8,9)$ & \\
\hline \multicolumn{5}{|l|}{ Socioeconomic condition* } \\
\hline Lower & $71(16,8)$ & $242(57,2)$ & $110(26,0)$ & 0.00 \\
\hline Higher & $317(24,3)$ & $629(48,2)$ & $360(27,6)$ & \\
\hline \multicolumn{5}{|l|}{ Physical activity } \\
\hline No & $231(22,5)$ & $514(50,1)$ & $281(27,4)$ & 0.44 \\
\hline Irregular & $66(19,6)$ & $171(50,9)$ & $99(29,5)$ & \\
\hline Regular & $91(24,8)$ & $186(50,7)$ & $90(24,5)$ & \\
\hline \multicolumn{5}{|l|}{ Tobacco use } \\
\hline Non-smoker & $301(22,4)$ & $698(51,9)$ & $347(25,8)$ & 0.03 \\
\hline Smoker & $87(22,7)$ & $173(45,2)$ & $123(32,1)$ & \\
\hline \multicolumn{5}{|l|}{ Alcohol consumption } \\
\hline No consumption & $252(23,4)$ & $556(51,6)$ & $270(25,0)$ & 0.03 \\
\hline Regular & $136(20,9)$ & $315(48,4)$ & $200(30,7)$ & \\
\hline \multicolumn{5}{|l|}{ Body Mass Index } \\
\hline Normal & $167(23,3)$ & $373(51,9)$ & $178(24,8)$ & 0.04 \\
\hline Overweight & $148(19,9)$ & $380(51,2)$ & $214(28,8)$ & \\
\hline Obese & $73(27,1)$ & $118(43,9)$ & $78(29,0)$ & \\
\hline \multicolumn{5}{|l|}{ Type of Service } \\
\hline Industrial maintenance & $169(27,7)$ & $180(29,5)$ & $261(42,8)$ & 0.00 \\
\hline Civil Works & $135(22,0)$ & $329(53,5)$ & $151(24,6)$ & \\
\hline
\end{tabular}


Table 1 General characteristic of the sample by levels of noise exposure (Continued)

\begin{tabular}{llll}
\hline Building cleaning & $33(9,4)$ & $261(74,1)$ & $58(16,5)$ \\
Others & $51(33,6)$ & $101(66,4)$ & $0(0)$ \\
Heat & & & $372(24,4)$ \\
$\quad$ Non-exposed & $385(25,2)$ & $769(50,4)$ & $98(48,3)$ \\
$\quad$ Exposed & $3(1,5)$ & $102(50,2)$ & $339(26,1)$ \\
Arterial Hypertension & & $648(49,9)$ & $131(30,5)$ \\
$\quad$ Normotensive & $312(24,0)$ & $223(51,9)$ & 0.02 \\
Hypertensive & $76(17,7)$ &
\end{tabular}

*Socioeconomic condition: Existent - presence of piped water + regular garbage collection + sewage system + electricity; absence: inexistence of at least one of the above factors.

male $(n=413 / 26.1 \%)$ and married workers $(n=249$ / $30.7 \%$ ). Hypertension was more likely associated with no regular physical activity $(\mathrm{n}=276 / 26.9 \%)$, tobacco use $(n=122 / 31.9 \%)$, alcohol consumption $(n=191 / 29.3 \%)$ and obesity ( $\mathrm{n}=121 / 45.0 \%)$.

Categorized age, gender, marital status, education, socioeconomic status, physical activity, use of tobacco, alcohol consumption and BMI were associated to the outcome (blood pressure level) and were considered for inclusion in the final multivariate model as possible confounding variables along with noise exposure (exposure variable) and the first order interaction term gender*noise. However, only age, gender, BMI and noise exposure were independently associated to arterial hypertension (Table 3). The positive association between noise exposure and high blood pressure was found at two categories of noise exposure when compared to a reference category of $\leq 75 \mathrm{~dB}(\mathrm{~A})$, 75-85 dB(A) (OR 1.56; IC95\% $1.13-2.17$ ) and $\geq 85 \mathrm{~dB}(\mathrm{~A})$ (OR 1.58; IC95\% 1.10 - 2.26).

\section{Discussion}

\section{Overview}

More than $80 \%$ of workers with high blood pressure in our sample were exposed to noise levels above $75 \mathrm{~dB}(\mathrm{~A})$, approximately $52 \%$ to levels between $75-85 \mathrm{~dB}(\mathrm{~A})$. In our final multivariate model, we were able to show that the exposure variable noise level and the co-variables age, sex and BMI were independently associated to high blood pressure. It is important to note that the same covariables are established risk factors for high blood pressure in the biomedical literature [29-33]. Workers exposed to noise levels $\geq 85 \mathrm{~dB}(\mathrm{~A})$ and those exposure to levels varying from $75-85 \mathrm{~dB}(\mathrm{~A})$ presented a $60 \%$ higher probability of presenting high blood pressure when compared to workers exposed to noise levels $\leq 75 \mathrm{~dB}(\mathrm{~A})$, after controlling for age, gender and BMI.

High blood pressure, just like any other noncommunicable diseases, is multifactorial in its causes and each separated risk factor has its own level of association to the blood pressure. In our final model, noise exposure association to blood pressure is weaker than the association between the other variables and the outcome. However, if the association is indeed casual and the prevalence of occupational noise exposure is high, such as the case of several types of industries, then the fraction of high blood pressure that could be attributable to noise exposure can be substantial.

\section{Literature review of non-hearing effects of noise exposure}

Our results are consistent with other studies that employed similar methodologies but different definitions for exposure and outcome. Some studies have observed the increase in blood pressure measures on workers exposed to noise but they have failed in characterizing such workers as hypertensive. Chang et al. [22] showed that both systolic and diastolic blood pressure were significantly higher among workers exposed to noise levels $\geq 85 \mathrm{~dB}(\mathrm{~A})$. Powazka et al. [34] observed an average increase in the systolic blood pressure of $5 \mathrm{mmHg}$ among workers at a steel factory exposed to $89 \mathrm{~dB}(\mathrm{~A})$. Tomei et al. [35] performed a meta-analysis to investigate the association between cardiovascular abnormalities and chronic occupational exposure to noise. They were able to show a statistically significant increase in the systolic and diastolic blood pressures only among workers exposed to an average noise level of $92 \mathrm{~dB}(\mathrm{~A})$. However, few authors have used a formal definition of high blood pressure when studying exposure to occupational noise. Narlawar et al. [36] described a higher prevalence of high blood pressure among 770 workers exposed to noise levels $\geq 98 \mathrm{~dB}(\mathrm{~A})$ at an iron and steel company in India. Souto Souza et al. [37] observed that the exposure to occupational noise to levels of $85 \mathrm{~dB}(\mathrm{~A})$ or more for more than 10 years was associated to high blood pressure among workers at an oil industry in Brazil, even after adjusting for age, educational level and obesity. The same association was not significant when time of exposure was not taken into account. Interestingly, Inoue et al. [38] studied 242 Japanese workers exposed to high noise levels and showed an inverse association between high blood pressure and noise level at workplace. 
Table 2 Association between sociodemographic and environmental variables and blood pressure level

\begin{tabular}{l} 
Variable \\
\hline Age (years) \\
$<30$ \\
$30-34$ \\
$35-39$ \\
$40-44$ \\
$45-49$ \\
$\geq 50$ \\
Gender \\
Female \\
Male \\
Marital status \\
Single \\
Married \\
Education \\
Up to incomplete elementary school \\
Complete elementary school \\
Incomplete middle school \\
Complete middle school \\
Incomplete high school \\
Complete high school \\
College/university (complete or not)
\end{tabular}

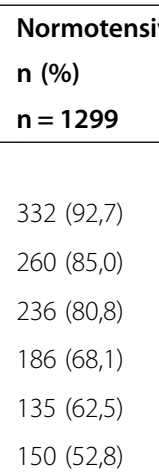

n (\%)

$n=430$

Socioeconomic condition*

Lower

Higher

Physical activity

No

Irregular

Regular

\section{Tobacco use}

Non-smoker

Smoker

\section{Alcohol consumption}

No consumption
Regular

Body Mass Index

Normal

Overweight

Obese

Type of Service

Industrial maintenance

Civil Works

$292(79,6)$
$619(86,2)$

$127(88,2)$

$1172(73,9)$

$738(80,3)$

$561(69,3)$

$56(69,1)$

$96(72,2)$

$256(73,1)$

$239(79,1)$

$157(77,7)$

$392(73,0)$

$103(83,1)$

$331(78,3)$

$968(74,1)$

$750(73,1)$

$257(76,5)$

$1038(77,1)$

$261(68,1)$

$839(77,8)$

$460(70,7)$

$532(71,7)$

$148(55,0)$

$464(76,1)$

$453(73,7)$
$26(7,3)$

0,00

$46(15,0)$

$56(19,2)$

$87(31,9)$

$81(37,5)$

$134(47,2)$

$17(11,8)$

0,00

$413(26,1)$

$181(19,7)$

0,00

$249(30,7)$

$25(30,9)$

0,07

$37(27,8)$

$94(26,9)$

$63(20,9)$

$45(22,3)$

$145(27,0)$

$21(16,9)$

$92(21,7)$

0,09

$338(25,9)$

$276(26,9)$

0,04

$79(23,5)$

$75(20,4)$

$308(22,9)$

0,00

$122(31,9)$

$239(22,2)$

0,00

$191(29,3)$

$99(13,8)$

0,00

$210(28,3)$

$121(45,0)$

$146(23,9)$

0,29

$162(26,3)$ 
Table 2 Association between sociodemographic and environmental variables and blood pressure level (Continued)

\begin{tabular}{lll}
\hline Building cleaning & $274(77,8)$ & $78(22,2)$ \\
Others & $108(71,1)$ & $44(28,9)$ \\
Heat & & $372(24,4)$ \\
Non-exposed & $1154(75,6)$ & $58(28,6)$ \\
Exposed & $145(71,4)$ & 0,19 \\
\hline
\end{tabular}

*Socioeconomic condition: Existent - presence of piped water + regular garbage collection + sewage system + electricity; absence: inexistence of at least one of the above factors.

The absence of adequate limits for non-hearing effects of noise exposure may result in the occurrence of health effects possibly associated to harmful exposures, but not identified. The importance of investigations of nonhearing effects associated to lower levels of noise exposures is supported by the results of the few studies that used $75 \mathrm{~dB}(\mathrm{~A})$ as the cut-off level. Gitanjali and Ananth (2004) were able to show abnormalities during the sleep phases for exposures to lower levels of noise, while Chang et al. (2003) showed transitory changes to blood pressure for similar noise exposure levels [28,39]. Chang et al. [40] studied workers from a screw factory in Taiwan and also showed a significant association between noise exposure to $\geq 70 \mathrm{~dB}(\mathrm{~A})$ and $\geq 80 \mathrm{~dB}(\mathrm{~A})$ and high blood pressure. We have decided to investigate the association between noise exposure and high blood pressure at three different levels, and we have demonstrated a higher prevalence of hypertension even at exposure levels considered safe by current legislations $(\leq 85 \mathrm{~dB}(\mathrm{~A}))$.

\section{Limitations}

Herein, we used a cross sectional design to address the main question of association between noise exposure and high blood pressure and this type of study design does not allow us to guarantee that exposure precedes the outcome, a condition to confirm a cause-effect association. However, it is unlikely that workers that initially had high blood pressure have been intentionally allocated to workplaces presenting higher levels of noise exposure. Besides, health effects of noise exposure may be time-dependent as demonstrated by Souto Souza et al. [37], and the cross sectional design did not allow us to consider time as a variable in our analysis. However, as oppose to their work, we were able to show an association even with no information about time of exposure.

Completeness and quality of data was one of the main limitations in our study. Data were collected as part of the annual mandatory health evaluation required by law in Brazil and no regular quality control measures required by

Table 3 Odds ratio and adjusted odds ratio for arterial hypertension among those exposed to noise

\begin{tabular}{|c|c|c|c|c|}
\hline Variable & Non-adjusted Odds Ratio & IC (95\%) & Adjusted Odds Ratio & IC (95\%) \\
\hline \multicolumn{5}{|l|}{ Age (years) } \\
\hline$<30$ & 1,00 (Ref.) & - & 1,00 (Ref.) & - \\
\hline $30-34$ & 2,26 & $1,36-3,75$ & 1,92 & $1,14-3,23$ \\
\hline $35-39$ & 3,03 & $1,85-4,97$ & 2,57 & $1,55-4,26$ \\
\hline $40-44$ & 6,00 & $3,72-9,59$ & 4,87 & $3,00-7,89$ \\
\hline $45-49$ & 7,66 & $4,71-12,44$ & 6,24 & $3,80-10,26$ \\
\hline$>=50$ & 11,41 & $7,18-18,10$ & 10,16 & $6,33-16,31$ \\
\hline \multicolumn{5}{|l|}{ Gender } \\
\hline Female & 1,00 (Ref.) & - & 1,00 (Ref.) & - \\
\hline Male & 2,63 & $1,57-4,42$ & 1,88 & $1,08-3,29$ \\
\hline \multicolumn{5}{|l|}{ Body Mass Index } \\
\hline Normal & 1,00 (Ref.) & - & 1,00 (Ref.) & - \\
\hline Overweight & 2,46 & $1,89-3,22$ & 2,12 & $1,60-2,81$ \\
\hline Obesity & 5,11 & $3,71-7,04$ & 4,46 & $3,16-6,29$ \\
\hline \multicolumn{5}{|l|}{ Noise* } \\
\hline$\leq 75 \mathrm{~dB}(\mathrm{~A})$ & 1,00 (Ref.) & - & 1,00 (Ref.) & - \\
\hline $75-85 \mathrm{~dB}(\mathrm{~A})$ & 1,41 & $1,05-1,89$ & 1,56 & $1,13-2,17$ \\
\hline$\geq 85 \mathrm{~dB}(\mathrm{~A})$ & 1,58 & $1,15-2,19$ & 1,58 & $1,10-2,26$ \\
\hline
\end{tabular}

${ }^{*}$ Controlled for age, gender and body mass index. 
a scientific research was in place during data collection. This may have influence not only the availability of the required variables but also the accuracy of some important information. Workers were classified as hypertensive during their routine annual mandatory health evaluations based on two blood pressure measures taken at one single occasion. Such approach may have created a selection bias and misclassified healthy individuals into hypertensive workers, leading to overdiagnosis and overmedication. In addition, some variables historically associated to high blood pressure, such as socioeconomic level [30], that could confound the studied association had not been collected as part of the annual evaluation and were unavailable to be tested. However, indicators of socioeconomic conditions such as sewage and trash collection and presence of piped water at home were available in the dataset, and we were able to create a composited indicator with such primary variables and use it as a proxy of socioeconomic status among the workers at the oil industry. The absence of association between the new indicator and high blood pressure may be real, but it may also indicate that the created indicator was not able to capture the real socioeconomic status among workers in our study. The use of personal protection equipment (PPE) such hearing protection may also determine different levels of exposure to noise [41]. Accurate information about the use of PPE was not available in the dataset.

\section{Public health relevance}

It has been shown that subcontractor workers are more exposed to inadequate work conditions $[42,43]$. Therefore, the high frequency of noise exposure at workplace and the high prevalence of high blood pressure described in our population confirm the importance of our study. Hypertensive workers may have the exposure to lower levels of occupational noise associated to the development or worsening of high blood pressure hypertension. However, high blood pressure may not be considered in health evaluations since noise exposure is situated in levels considered safe according to current legislation. Therefore, it is important that noise exposure limits are established aiming at preventing both hearing and non-hearing health effects.

\section{Conclusion}

The main idea of our study was to give elements to support the hypothesis of an association between noise exposure and high blood pressure. However, there is no indication why our results could not be applied to locals with similar noise exposure. Even with all limitations, we believe that our results are important as one further data presenting an association between noise exposure and high blood pressure due to the uncertainty still surrounding the issue in the biomedical literature. The association between noise exposure and auditory effects is well established in the environmental epidemiology, but the same is not true with non-auditory effects. Moreover, it has been shown that the noise exposure levels to be considered in the case of non-auditory effects may not be the same as in the case of auditory effects. Our results may contribute to emphasize the importance of searching for adverse health effects on exposure levels considered safe and alert decision makers and regulatory agencies about the importance of establishing more accurate noise exposure limits so that the health of workers is not compromise. The study may also serve to increase workers' awareness about the occupational effects on health.

\section{Abbreviations}

BMI: Body Mass Index; CEP/ENSP: Ethics Committee at the National School of Public Health; HEG: Homogeneous Exposure Groups; OR: Odds ratio; PPE: Personal protection equipment; WBGTI: Wet Bulb Globe Thermometer Index; WHO: World Health Organization; YLLs: Years of life lost due to premature mortality.

\section{Competing interests}

The authors declare that they have no competing interests.

\section{Authors' contributions}

TCFS conceived the study, carried out data collection and data analysis; ARSP participated in the study design, statistical analysis and draft manuscript; MM participated in the study design and coordination and helped draft the manuscript. All authors read and approved the final manuscript.

\section{Acknowledgements}

Authors thank Darci Garios and Dr Sérgio Bastos for supporting the work and provide access to the dataset. We also thank the "Coordenação de Aperfeiçoamento de Pessoal de Nível Superior" (CAPES) for financial support of TCFS. The funding body had no role in the design, collection, analysis, and interpretation of data, in the writing of the manuscript, and in the decision to submit it for publication.

\section{Author details}

${ }^{1}$ Centro de Estudos da Saúde do Trabalhador e Ecologia Humana, Escola Nacional de Saúde Pública Sergio Arouca, Fundação Oswaldo Cruz (CESTEH/ ENSP/Fiocruz), Rua Leopoldo Bulhões 1480, Manguinhos, Rio de Janeiro/RJ, Brazil. ${ }^{2}$ Departamento de Ciências Biológicas, Escola Nacional de Saúde Pública Sergio Arouca, Fundação Oswaldo Cruz (DCB/ENSP/Fiocruz), Rua Leopoldo Bulhões 1480, Manguinhos, Rio de Janeiro/RJ, Brazil.

Received: 26 November 2014 Accepted: 23 March 2015

Published online: 03 April 2015

\section{References}

1. Axelsson A, Prasher D. Tinnitus induced by occupational and leisure noise. Noise Health. 2000;2(8):47-54.

2. Dias A, Cordeiro R, Corrente JE, Gonçalves CG. Association between noise-induced hearing loss and tinnitus. Cad Saude Publica. 2006;22(1):63-8.

3. Gomes J, Lloyd O, Norman N. The health of the workers in a rapidly developing country: effects of occupational exposure to noise and heat. Occup Med (Lond). 2002;52(3):121-8.

4. Merino FO, Zapata FO, Kulka AF. Ruido laboral y su impacto em salud. Ciencia \& Trabajo. 2006;8:5.

5. Concha-Barrientos M, Campbell-Lendrum D, Steenland K. Occupational noise: assessing the burden of disease from work-related hearing impairment at national and local levels. In: Environmental Burden of Disease Series. Geneva: World Health Organization; 2004.

6. King RP, Davis JR. Community noise: health effects and management. Int J Hyg Environ Health. 2003;206(2):123-31. 
7. Spreng M. Noise induced nocturnal cortisol secretion and tolerable overhead flights. Noise Health. 2004;6(22):35-47.

8. Babisch W. Stress hormones in the research on cardiovascular effects of noise. Noise Health. 2003;5(18):1-11.

9. Dias A, Cordeiro R, Gonçalves CG. Occupational noise exposure and work accidents. Cad Saude Publica. 2006;22(10):2125-30.

10. Picard M, Girard SA, Simard M, Larocque R, Leroux T, Turcotte F. Association of work-related accidents with noise exposure in the workplace and noise-induced hearing loss based on the experience of some 240,000 person-years of observation. Accid Anal Prev. 2008;40(5):1644-52

11. Ising $H$, Kruppa B. Health effects caused by noise: evidence in the literature from the past 25 years. Noise Health. 2004;6(22):5-13.

12. Berglund B, Lindvall T, Schwela DH. Guidelines for Community Noise. In: World Health Report. Geneva: World Health Organization; 1999.

13. Lozano R, Naghavi M, Foreman K, Lim S, Shibuya K, Aboyans V, et al. Global and regional mortality from 235 causes of death for 20 age groups in 1990 and 2010: a systematic analysis for the Global Burden of Disease Study 2010. Lancet. 2012;380(9859):2095-128.

14. Lim SS, Vos T, Flaxman AD, Danaei G, Shibuya K, Adair-Rohani H, et al. A comparative risk assessment of burden of disease and injury attributable to 67 risk factors and risk factor clusters in 21 regions, 1990-2010: a systematic analysis for the Global Burden of Disease Study 2010. Lancet. 2012;380 (9859):2224-60.

15. Global Health Observatory Data Repository. Blood pressure: raised blood pressure (SBP $\geq 140 \mathrm{OR} D B P \geq 90$ ). Data by WHO region. 2008 [http://apps. who.int/gho/data/view.main.2540?lang=en]

16. Sociedade Brasileira de Cardiologia, Sociedade Brasileira de Hipertensão e Sociedade Brasileira de Nefrologia. VI Diretrizes Brasileiras de Hipertensão. Arq Bras Cardiol. 2010;95(Suppll):50.

17. Babisch W. Epidemiological Studies of the Cardiovascular effects of Occupational Noise - A Critical Appraisal. Noise Health. 1998;1(1):24-39.

18. Babisch W. The noise/stress concept, risk assessment and research needs. Noise Health. 2002;4(16):1-11.

19. Goyal S, Gupta V, Walia L. Effect of noise stress on autonomic function tests. Noise Health. 2010;12(48):182-6.

20. Chang TY, Wang VS, Hwang BF, Yen HY, Lai JS, Liu CS, et al. Effects of co-exposure to noise and mixture of organic solvents on blood pressure. J Occup Health. 2009:51(4):332-9.

21. Chang TY, Liu CS, Huang KH, Chen RY, Lai JS, Bao BY. High-frequency hearing loss, occupational noise exposure and hypertension: a cross-sectional study in male workers. Environ Health. 2011;10:35.

22. Chang TY, Hwang BF, Liu CS, Chen RY, Wang VS, Bao BY, et al. Occupational noise exposure and incident hypertension in men: a prospective cohort study. Am J Epidemiol. 2013;177(8):818-25.

23. Sbihi H, Davies HW, Demers PA. Hypertension in noise-exposed sawmill workers: a cohort study. Occup Environ Med. 2008;65(9):643-6.

24. WHO: Obesity and overweight. In: Fact sheet. World Health Organization. 2014. http://www.who.int/mediacentre/factsheets/fs311/en/.

25. Giampaoli E, Saad IFdSD, da Cunha IÂ. Norma de Higiene Ocupacional $n^{\circ}$ 06 (NHO - 06): Avaliação da exposição ocupacional ao calor. Edited by FUNDACENTRO. São Paulo: Ministério do Trabalho e Emprego; 2002: 46

26. Chobanian AV, Bakris GL, Black HR, Cushman WC, Green LA, Izzo JL, et al. Seventh report of the joint national committee on prevention, detection, evaluation, and treatment of high blood pressure. Hypertension. 2003:42(6):1206-52.

27. Giampaoli E, Saad IFSD, da Cunha IdÂ. Norma de Higiene Ocupacional $n^{\circ}$ 01 (NHO - 01): Avaliação da exposição ocupacional ao ruído. Edited by FUNDACENTRO. São Paulo: Ministério do Trabalho e Emprego; 2001: 40

28. Gitanjali B, Ananth R. Effect of occupational noise on the nocturnal sleep architecture of healthy subjects. Indian J Physiol Pharmacol. 2004;48:8.

29. Carneiro G, Faria AN, Ribeiro Filho FF, Guimarães A, Lerário D, Ferreira SR, et al. Influence of body fat distribution on the prevalence of arterial hypertension and other cardiovascular risk factors in obese patients. Rev Assoc Med Bras. 2003:49(3):306-11.

30. da Costa JS, Barcellos FC, Sclowitz ML, Sclowitz IK, Castanheira M, Olinto MT, et al. Hypertension prevalence and its associated risk factors in adults: a population-based study in Pelotas. Arq Bras Cardiol. 2007;88(1):59-65.

31. Feijão A, Gagelha F, Bezerra A, Oilveira A, Silva M, Lima J. Prevalência de excesso de peso e hipertensão arterial, em população urbana de baixa renda. Ara Bras Cardiol. 2005;84:5.
32. Liberman A. Aspectos epidemiológicos e o impacto clínico da hipertensão no indivíduo idoso. Revista Brasileira de Hipertensão. 2007;14:4.

33. Scher LML, Nobre F, Lima NKC. O papel do exercício físico na pressão arterial em idosos. Revista Brasileira de Hipertensão. 2008;15:4.

34. Powazka E, Pawlas K, Zahorska-Markievicz B, Zejda JE. A cross-sectional study of occupational noise exposure and blood pressure in steelworkers. Noise \& Health. 2002;5:8.

35. Tomei G, Fioravanti M, Cerratti D, Sancini A, Tomao E, Rosati MV, et al. Occupational exposure to noise and the cardiovascular system: a meta-analysis. Sci Total Environ. 2010;408(4):681-9.

36. Narlawar UW, Surjuse BG, Thakre SS. Hypertension and hearing impairment in workers of iron and steel industry. Indian J Physiol Pharmacol. 2006;50:7.

37. Souto Souza NS, Carvalho FM, de Cássia Pereira Fernandes R. Arteria hypertension among oil-drilling workers exposed to noise. Cad Saude Publica. 2001;17(6):1481-8.

38. Inoue M, Laskar MS, Harada N. Cross-sectional study on occupational noise and hypertension in the workplace. Arch Environ Occup Health. 2005;60(2):106-10.

39. Chang TY, Jain RM, Wang CS, Chan CC. Effects of occupational noise exposure on blood pressure. J Occup Environ Med. 2003;45(12):1289-96.

40. Chang TY, Liu CS, Young LH, Wang VS, Jian SE, Bao BY. Noise frequency components and the prevalence of hypertension in workers. Sci Total Environ. 2012;416:89-96.

41. Stokholm ZA, Bonde JP, Christensen KL, Hansen AM, Kolstad HA Occupational noise exposure and the risk of hypertension. Epidemiology. 2013;24(1):135-42.

42. Antunes R. Afinal, Quem é a Classe Trabalhadora Hoje? Estudos do Trabalho. In: Revista da Rede de Estudos do Trabalho. vol. Ano II. 2008.

43. Barros PCR, Mendes AMB. Sofrimento psíquico no trabalho e estratégias defensivas dos operários terceirizados da construção civil. Psico-USF. 2003;8:8.

\section{Submit your next manuscript to BioMed Central and take full advantage of:}

- Convenient online submission

- Thorough peer review

- No space constraints or color figure charges

- Immediate publication on acceptance

- Inclusion in PubMed, CAS, Scopus and Google Scholar

- Research which is freely available for redistribution 